of the light-water-cooled and gas-cooled types, and possibly in later years the organic cooled type.

A centre for nuclear research and development is being completed at Tokai-mura, and an institute for plasma physies is being set up on the Higashi-yama campus of Nagoya University. The institute will consist of seven research divisions covering theoretical studies and high-temperature generation experiments. An investigation of the required high-voltage supply and of the pinch effect was initiated in 1957 at Osaka University and since then plasma physics research has been carried out at Tohoku University, Tokyo University of Education, Tolyo University, Nagoya University and Kyoto University. At present there are approximately sixteen different forms of apparatus planned or under construction by twelve plasma physics research groups in Japan.

In the chapter of the annual report dealing with uses of radiation it is stated that most of the radioisotopes used in Japan are imported. During 1960 a total of 55,000 curies were imported, consisting mainly of cobalt-60, phosphorus-32 and iodine-131. By the end of March 1961, 867 establishments. representing modical organizations, private firms and universities and research institutes, in approximately equal numbers, were using radioisotopes. JAERI is preparing for full-scalo production of radioisotopos in order to fulfil the future domestic requiremonts. The first six isotopes to be produced will be sodium-24, phosphorus-32, sulphur-35, potassium-42 and gold-198.

Other chapters of the report deal with nuclear equipment and materials; radioactivity surveys; treatment of radioactive waste; regulations and radiation protection; and training of scientists and engineers. It is considered that $11,000-13,000$ scientists and engineers in nuclear energy will be required in the next ten years and it will be necessary to train and educate some 8.000 in those ten yoars. At present, the possible number to be trainod each year is 150-200 at universities, about 200 at JAERI and NIRS, and 90 at institutions outside Japan.

S. WeINTROUB

\title{
GASEOUS OPTICAL MASERS
}

$\mathrm{B}$ ELL Telephone Laboratories Inc. have issued a brochure describing rocent work at Murray Hill, New Jersey, on the gaseous optical maser. The Bell Laboratories are the most active single organization in this field, and have recently extended the range of wave-lengths available from the maser. The first type of gas discharge optical maser, initially operated by Javan, Bennett and Herriott in February 1961, used a helium-neon mixture and produced an output at $1 \cdot 15 \mu$. Since then, population inversion sufficient to support masor oscillation has been obtained in gas discharges in pure inert gases (helium, neon, argon, krypton and xenon) providing a total of fourteen different wave-lengths in the range $1 \cdot 618-2 \cdot 189 \mu$. Inversion has also been achioved between two levels of the oxygen atom by dissociating molocular oxygen in collisions with an inert gas atom, either argon or neon, in a metastable state, using a discharge in a mixture of oxygen and the inert gas. The maser output in this case is at $8446 \AA$. The shortest wave- length, and consequently the most useful for applica. tions involving high-efficiency photoelectric detection, lies in the visible at $6328 \AA$, and has been obtained from a helium-noon maser with mirrors having a high reflectivity at this wave-length.

Power outputs of these now masers are in the range from a fraction of $1 \mathrm{~mW}$ to $10 \mathrm{~mW}$. The experimental work has been done with masers using external confocal mirrors and a discharge tube having end windows at the Brewster angle to the emergent, beam, thus eliminating, for the appropriate plane of polarization, reflexion and consequent energy loss at the windows.

The information in the Bell Telephone Laboratories brochure is an indication of the great effort which is being put into the development of the gaseous maser, which is already being applied to a number of research problems and may, in the future, find uses in the communications field.

J. H. SANDERS

\section{EFFECT OF MOISTURE MOVEMENT OF NATURAL AGGREGATE ON CONCRETE}

COME years ago investigations of concrete failure, $S$ thought to be due to the chemical reactivity of certain rock-types involved with the cement during hydration, were carried out in the United States and later in the United Kingdom. Arising from this, certain rock-types, for example, some dolerites, especially those containing the chlorite mineral chlorophaeite, became suspect. Experimental work was based largely on chemical and petrological studies to determino potential reactivity with alkalis released during hydration of Portland cement in concrete involving aggregates dominated by supposedly unstable components. Methods of determination of such components were tentatively laid down by the American Society for Testing Materials (Proc., 48, 1948; and Standards, 1952), and in the United Kingdom F. E. Jones has discussed the subject in some detail (National Building Research Studies, Nos. 14, 15, 16; 1952).
The evidence from this experimental work cannot be considered as conclusive; in fact, some of it is so conflicting as to raise grave doubts on the alleged chemical vulnerability of certain dolerite aggregates, including natural gravels containing these rockpebbles, or others loaded with acid volcanic types, also suspect. There is at present what appears to be a more convincing explanation of this type of concrete failure. In a paper by L. C. Snowdon and A. G. Edwards, entitled "The Moisture Movement of Natural Aggregate and its Effect on Concrete" (Concrete Research, 14, 109; 1962), is described the work of the Scottish Laboratory of the Building Research Station on the failure of pre-cast concrete products in which certain crushed dolerite aggregates had been used. It is pointed out that in Scotland dolerite aggregate is extensively used in concrete.

The interest of the Department concerned ". . . became focused on its performance in 1952 when 